\title{
Bi-Level Model on Freight Distribution Network Integration in Archipelagic Region with Milk Run Time Windows and Uncertainty
}

\author{
Windra Priatna Humang ${ }^{1}$, Sigit Pranowo Hadiwardoyo ${ }^{2}, \mathrm{Nahry}^{3}$ \\ Department of Civil Engineering, Faculty of Engineering, Universitas Indonesia, Depok 16242, Indonesia \\ ORCID: ${ }^{1)}$ 0000-0002-7549-9147; 2)0000-0001-8734-4794, 3)0000-0003-2116-8470
}

\begin{abstract}
As an archipelagic country, Indonesian government gives subsidy and public service obligation (PSO) to Sea Tollway, Pelni and Pioneer vessels to distribute freights to small islands. These three types of vessel are independently managing their own time and network. As the result, the distribution network becomes unintegrated and not optimal in suppressing transport cost and subsidy-PSO. The aim of this paper is to develop and implement bi-level model in sea transport network integration on freight distribution system on archipelagic territory. Upper level model is intended to minimalize the number of operated vessels, while lower level model is intended to determine the route that maximize the profit in freight distribution that involves Sea Tollway, Pelni and Pioneer vessels.

The application of genetic algorithm (GA) in problem solving on milk run time windows (MRTW) network can accommodate the uncertainty variable, namely load and wave height. The result of model validation with empirical test on the case in Indonesia shows that the model can gives optimal value in solving the network integration problem. The sensitivity analysis shows that the number of operating vessels and the uncertainty variable intervention on the determination of vessel route affect the clustering. The management of vessel route should be integrated in real time by factoring the wave height variable, with consequence that the received gross profit is decreasing by $11,8 \%$ when compared to the condition without the wave height consideration.
\end{abstract}

Keywords: integration network, subsidy-PSO, bi-level, genetic algorithm, archipelagic.

\section{INTRODUCTION}

The common paradigm used in vessel service to improve the economy is "ship follows the trade". However, Indonesia is an archipelagic country, therefore the paradigm used is "ship promotes the trade", when factoring the vast geographical location and limitation in reaching isolated, outermost and border islands [1]. To guarantee the continuity of freight availability on the islands and to suppress transportation cost, Indonesian government gives subsidy and public service obligation (PSO) to Sea Tollway, Pelni, and Pioneer vessels. In 2018, the government gave PSO-subsidy of 447 billion to Sea Tollway, 1.860 billion to Pelni and 1.100 billion to Pioneer. However, subsidy-PSO has not increased the effectivity of sea transport service [2].
Transport service of Sea Tollway, Pelni and Pioneer that is managed by different operator tend to be stand alone, namely in the network operation on service hour, even though institutionally the coordination is under the Ministry of Transportation. 2018 data shows that the Sea Tollway has 13 vessel routes, 3.084 passenger capacity, 500 ton cargo capacity and 98 Teus. Pioneer vessels serve on 96 routes, have size of $500-1.000$ DWT/1.200 - 2.000 GT, with cargo capacity of 500-1000 ton. There are many problems in the service of the three vessels, namely the low connectivity, caused by the limited number of vessels which does not compare with the number of destination port. This condition causes the high duration of voyage time, which is $18-23$ days in one round voyage.

The geographical condition of eastern Indonesia, that consists of Maluku, North Maluku, East Nusa Tenggara, West Nusa Tenggara, Papua and West Papua demands the distribution system to serve around 174 islands (2,3\% of total island in eastern Indonesia). In an ideal condition, proper vessel availability is needed in a vast service area. Each inter-vessel network/route must be connected and integrated to guarantee the freight distribution. Integration is not only in route management but also service time improvement in the node. The low level of network integration and integration in port node cause the high transport cost borne by operator and lead to the high subsidy-PSO given by government. Therefore, network integration is expected to optimize the income of vessel operator which will reduce the subsidy-PSO.

In the last decade the topic regarding integration of freight distribution network has been extensively researched. Researches about solution method and network model of freight distribution with multimode transportation has been compiled by SteadieSeifi et al. [3] and Sun et al. [4]. On the last few years, the development of integration model is focused on the inclusion of uncertainty variables. Researches that include uncertainty variables in their model are Bai et al. [5], Meng et al. [6], Lium et al. [7], Garrido and Mahmassani, [8], and Sanchez-Rodrigues et al. [9] with demand variable. Song et al. [10] and Olivo et al. [11] with empty container reposition variable Demir et al. [12] and Chalumuri, R.S., \& Yasuo, A. [13] with travel time variable. Other paper that develop vessel route management system with wave limitations are conducted by Vettor R, and Soares C [14], and Walther, L et al. [15], although they are limited on one type of vessel.

In addition to uncertainty variables, the most frequently used variables are measurable variable and certain variable. Several 
certain variables are used by Zhang et al. [16] to develop integration model in order to reduce the distribution cost and $\mathrm{CO}^{2}$ emission with distance, cost, vessel speed, handling time, sailing time, and vessel capacity variables. Halim et al. [17] uses number of ports, number of distribution center, transportation cost, port distance, distribution center operational cost, distribution center capacity, and penalty variables. Ghane-Ezabadi \& Vergara [18] use hub number, fixed cost, demand, transportation cost and distribution time variables.

The currently developing network integration of freight distribution in sea transport is stochastic and real time data, where system will adjust with real condition on the field. A research by $\mathrm{Fu}$ et al. [19] regarding simulasion based optimization (SBO) is a decent stochastic programming to solve stochastic problem that is used further by Oliveira and Montevechi [20] and Chica et al. [21]. A paper by Layeb et al. [22] developed stochastic programming simulation by simplifying uncertainty variables to achieve on time full delivery (OTFD) of 90\%. Güner et al. [23] also has developed dynamic route network integration with traveling salesman program (TSP) to determine milk run route. The model developed by Güner et al. [23] uses network and real data in determining the transportation cost and voyage time for optimal distribution.

Next, bi-level model has been used by Zhang and Xu [24] which is proven to increase profit, where the upper level is used in the logistical network integration while lower level is used to determine demand customer as uncertainty variable. Saranwong and Likasiri [25] also developed upper level model to determine the distribution central location and lower level to minimalize the total customer cost. Essentially, bilevel model is very suitable for decision making system, namely on case of Parvasi et al. [26], Bingfeng et al. [27] dan Liu and Ceder [28] who modeled bus route and found the best route.

This paper is a continuity from previous research which discovered the factors that affect the integration of sea transport network for freight [29] and research on clustering model of freight distribution system on archipelagic region [30]. Based on those researches, this paper will develop bilevel programming model to resolve the problem on distribution network optimization by observing the affecting factors from those researches. Upper level model is intended to determine the optimal number of vessels for freight distribution, while lower level model is intended to solve problems in network optimization by including wave height, a stochastic variable, in line with the archipelagic condition in Indonesia, where the vessels is very vulnerable when sailing in high wave, especially Pioneer vessels.

In addition to wave height, the uncertainty in demand number which is fluctuate in destination port will also be factored in the developed bi-level model. Every port located in isolated, outermost and borderareas must be served with consequence of high transportation cost. The constructed model must be able to be applied in real time, with possibility of reroute if it faces uncertainty obstacle [5]. The new contribution from this paper is uncertainty variables, namely demand fluctuation and wave height, and the solution method used is genetic algorithm (GA) approach, milk run time windows (MRTW) and real time data simulation.

In addition to this introduction, this paper consists of three other sections. Second section presents methodology that covers problem description, network integration suggestion, bi-level development model, and algorithm. Second section presents computational experiments that covers empirical test and sensitivity analysis. Fourth section presents research conclusion.

\section{METHODOLOGY}

\section{II.1 Problem Description}

The characteristics of current network causes the high cost that must be incurred in freight distribution process, long voyage time, and low network connectivity. Therefore, the analysis of modelling system is started by identifying the characteristics of the current distribution system network, namely:

- Main port (level I) as port of origin for Sea Tollway and Pelni, this port includes Port of Tanjung Priok, Port of Tanjung Perak and Port of Makassar.

- Collector port (level II) as port of destination for Sea Tollway and Pelni, but becomes port of origin for Pioneer vessels.

- Destination port (level III) as final port that becomes the port of destination for Pioneer vessels.

In every route of Sea Tollway, Pelni, and Pioneer transport there is transhipment port, which is a load transfer point between Sea Tollway and Pioneer vessels, Pelni and Pioner vessels. The routes are prone to be fixed route and adapt twoway route, which comes from port of origin to several ports of destination, and must pass the previous ports to return to port of origin. As transport that receives subsidy-PSO, every created route is an order from government. Therefore, all ports must be visited without searching if there is cargo in the port. The cargo type of Sea Tollway and Pelni vessel is Container (Non Mixable Product) while Pioneer vessel is general cargo (Mixable Product).

\section{II.2 Network Integration Suggestion}

The implemented system integration is related to the combination of tactical and operational planning. On tactical planning, the locations of port of destination are clustered to minimalize the coverage of Pioneer vessel service area, therefore increasing the frequency of visiting vessel in the ports. Meanwhile, operational planning is conducted in the process of real-time resource allocation because of the wave height and demand fluctuation factors.

The consideration in modifying network system is the wave factor uncertainty, and often becomes the obstacle in freight distribution, especially for Pioneer vessels because of its small vessel size. Being archipelagic region with small island clusters and far distance between ports cause the long duration of vessel intermediate stop frequency on ports in one round voyage. Therefore, limitation on maximum port distance is 
needed, especially ports served by Pioneer. This limitation is simulated in clustering area system for Pioneer vessel route.

The illustration of suggested tiered network system based on milk run time windows (MRTW) pattern and real time accommodation of uncertainty variable can be seen in Figure 1.

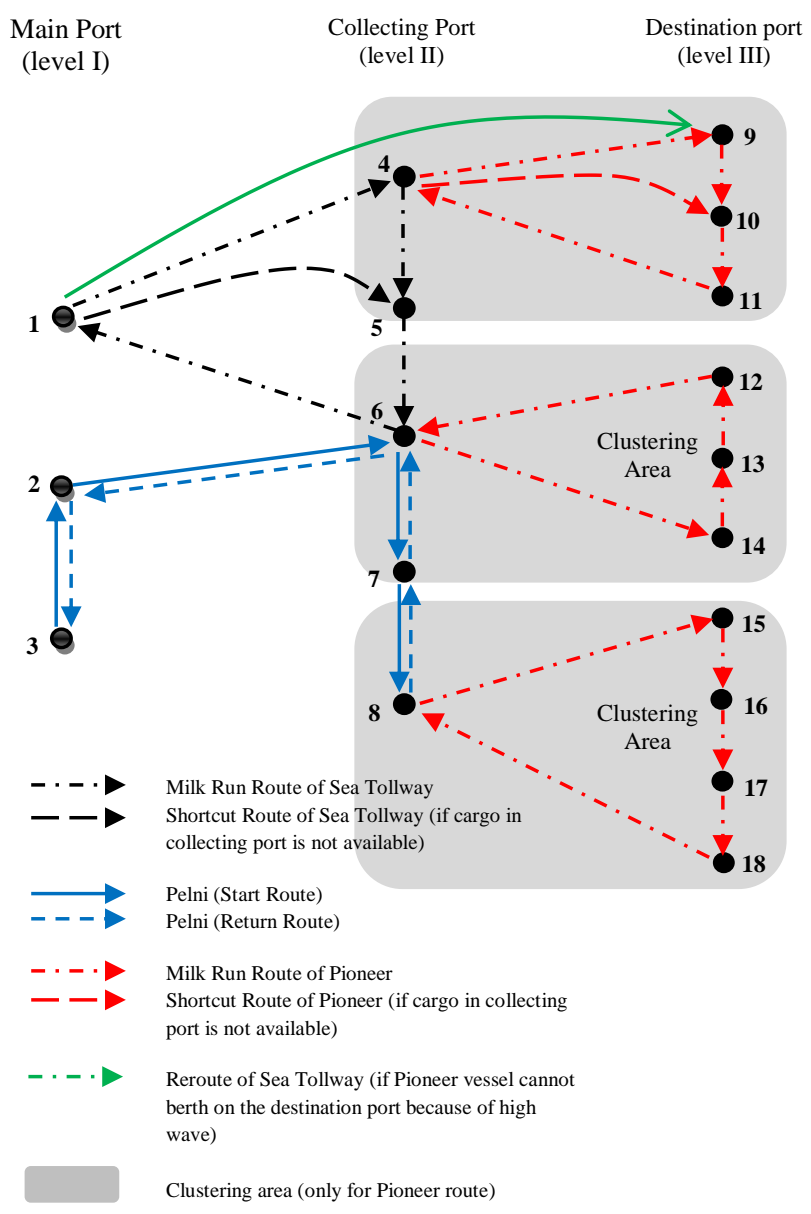

Fig. 1. The Suggested Distribution Network System

Based on Figure 1, network is modified by changing the route pattern of Sea Tollway and Pioneer vessels that initially is back-and-forth (2 way) system to become Milk Run (loop) system. Meanwhile, route of Pelni vessel is not changed because the current pattern is still efficient in loading passengers, where the main purpose of Pelni vessel is increasing the passenger accessibility and freight distribution, which are complementary function. The network is integrated by setting the time windows in ports for certainty in vessel's time of arrival. Clustering system is implemented to minimalize the size of service area, therefore minimalizing transportation cost. To accommodate uncertainty condition, information technology is implemented which involves prediction of sea wave height and cargo number in rerouting the network when there is no cargo to load and unload in destination port. There is a possibility for shortcut route if there is no cargo to load and unload in the destination port of Sea Tollway and Pioneer. If there is high wave (in real time) in the collecting port and Pioneer vessel cannot serve, Sea Tollway Vessel will serve the port.

\section{II.3 Model Development}

This section presents the characteristics of the system that is equationted with bi-level model. This model is hierarchical, connected to the problems in upper level and lower level. Each hierarch has its own objectives and related with each other. In this case, the problem in upper level is shown to determine the number of most optimal vessels for freight distribution process. Based on the output of the upper level problem, lower level problem will accommodate the number of vessels and optimize the vessel network based on the highest profit. The framework of the suggested bi-level programming is illustrated in Figure 2.

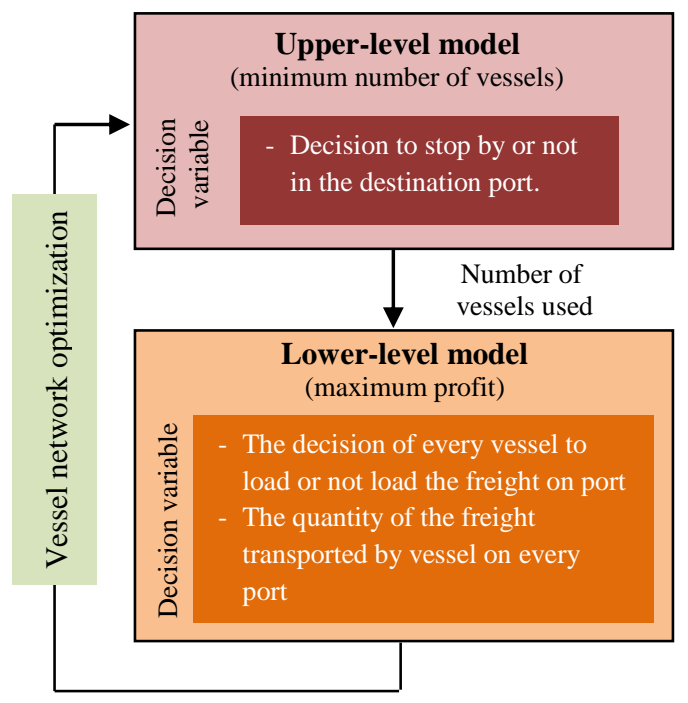

Fig. 2. Framework for bi-level models

\section{II.3.1 Notation}

We develop scholastic model of Milk Run Time Windows (MRTW), an expansion from Travelling Salesman Problem (TSP) model. The link equationtion that is defined as Graph G $(\mathrm{V}, \mathrm{A})$ involves the collection of port nodes $\mathrm{U}, \mathrm{P}$ and $\mathrm{R}$. We use three ports, which are main port collection $\mathrm{U}),-u=$ $\{1,2,3, \ldots u\}$, Collecting port collection, $(P),-p=\{1,2,3, \ldots p\}$, and destination port collection $R),-r=\{1,2,3, \ldots r\}$. The types of vessel used are Sea Tollway (TL) vessel, Pelni (PL) vessel and Pioneer (PR) vessel. The mathematical model follows the following notation.

\section{Parameter:}

$Z_{T L} \quad=$ maximum profit of Sea Tollway vessel (Rp)

$Z_{P L} \quad=$ maximum profit of Pelni vessel (Rp)

$Z_{P R} \quad=$ maximum profit of Pioneer vessel (Rp)

$n_{T L} \quad=$ number of Sea Tollway vessels operating in one route (unit)

$n_{P L} \quad=$ number of Pelni vessels operating in one route (unit)

$n_{P R} \quad=$ number of Pioneer vessels operating in one route (unit)

$\Phi_{T L}=$ cost per distance unit to transport cargo with Sea Tollway vessel (Rp/mile/TEUs)

$\varphi P L=$ cost per distance unit to transport cargo with Pelni vessel (Rp/mile/TEUs)

$\Psi_{P R}=$ cost per distance unit to transport cargo with Pioneer vessel (Rp/mile/ton)

$w^{u p}=$ distance from port $-u$ toport $-p$ (mile)

$z^{p r} \quad=$ distance from port $-p$ to port $-r$ (mile) 
International Journal of Engineering Research and Technology. ISSN 0974-3154 Vol.13, No.5 (2020), pp. 831-841

(C) International Research Publication House. https://dx.doi.org/10.37624/IJERT/13.5.2020.831-841

$D_{\pi}^{g}=$ total cargo request on port $-p$ with Sea Tollway vessel (TEUs)

$D_{P I}^{g}=$ total cargo request on port $-p$ with Pelni vessel (TEUs)

$D_{P R}^{7}=$ total cargo request on port $-r$ with Sea Tollway vessel (Ton)

$D^{r}{ }_{R}^{p}=$ Sea Tollway vessel demand estimation (TEUs)

$D_{P I}^{r E}=$ Pelni vessel demand estimation (TEUs)

$D_{P S}^{r V}=$ Pioneer vessel demand estimation (Ton)

$t_{I L}^{g}=$ average docking time of Sea Tollway vessel in port $-p$ (hour)

$t_{P R}^{F} \quad=$ average docking time of Pioneer vessel in port $-r$ (hour)

$T_{b_{m}}^{p} T_{I}=$ loading time of Sea Tollway vessel in port $-p$ per cargo unit (hour/TEUs)

$T_{b m P L}^{F}=$ loading time of Pelni vessel in port $-p$ per cargo unit (hour/TEUs)

$T_{b M P S}^{*}=$ loading time of Pioneer vessel in port $-r$ per cargo unit (hour/ton)

$T_{5 I}^{p} \quad=$ freight storage time in port $-p$ (day)

$T_{\text {gI }}^{\gamma}=$ freight storage time in port $-r$ (day)

$\mathrm{C}_{\text {fII }}=$ fuel cost per Sea Tollway vessel distance unit $(\mathrm{Rp})$

$C_{f I I}=$ fuel cost per Pelni vessel distance unit (Rp)

$\mathrm{C}_{f P R}=$ fuel cost per Pioneer vessel distance unit (Rp)

$C_{\text {berI }}^{p}=$ loading cost of Sea Tollway vessel in port $-p$ (Rp/TEUs)

$\mathrm{C}_{\mathrm{b} P \mathrm{FI}}^{\mathrm{F}}=$ loading cost of Pelni vessel in port $-p$ (Rp/TEUs)

$C_{b M R R}^{V}=$ loading cost of Pioneer vessel in port $-r$ (Rp/ton)

$\mathrm{C}_{\mathrm{si}}^{p}=$ freight storage cost in port $-p(\mathrm{Rp} / \mathrm{TEUs})$

$C_{g 1}^{r}=$ freight storage cost in port $-r(\mathrm{Rp} /$ ton $)$

$C_{i k}=$ container inventory cost $(\mathrm{Rp} / \mathrm{TEUs} /$ day $)$

$C_{i g}=$ general cargo inventory cost $(\mathrm{Rp} / \mathrm{Ton} /$ day $)$

$V_{T L}=$ average speed of Sea Tollway vessel (mile/hour)

$V_{P L} \quad=$ average speed of Pelni vessel (mile/ hour)

$V_{P R}=$ average speed of Pioneer vessel (mile/hour)

$V C_{T L}=$ capacity of Sea Tollway vessel (TEUs)

$V C_{P L}=$ capacity of Pelni vessel (TEUs)

$V C_{P R}=$ capacity of Pioneer vessel (Ton)

Lf $=$ load factor $(\%)$

$n_{t} \quad=$ planned number of trips

$T_{T L}=$ time horizon in one round voyage of Sea Tollway vessel, which is 15 days

$T_{P L}=$ time horizon in one round voyage of Pelni vessel, which is 20 days

$T_{P R}=$ time horizon in one round voyage of Pioneer vessel, which is 10 days

$x^{r}=$ port pool depth $-r(\mathrm{~m})$

$£_{T L} \quad=$ draft of Sea Tollway Vessel (m)

$\delta_{I L}^{F}=$ binary value of 1 if there is freight to be loaded in port $-p$ by Sea Tollway vessel; 0 if it is otherwise,

$\lambda_{\mathrm{PR}}^{\mathrm{T}}=$ binary value of 1 if there is freight to be loaded in port $-r$ by Pioneer vessel; 0 if it is otherwise,

$\xi_{r} \quad=$ binary value of 1 if the height of the wave around port $-r<$ 3 meter; 0 , if the height of the wave around port $-r \geq 3$ meter

Decision variable:

$\alpha^{4} \quad=$ freight quantity from port $-u$ to port $-p$ with Sea Tollway vessel (TEUs)

$\beta^{4 p}=$ freight quantity from port $-u$ to port $-p$ with Pelni vessel (TEUs)

$\sigma^{p v} \quad=$ freight quantity from port $-p$ to port $-r$ with Pioneer vessel (ton)
$x_{T L}^{u p} \quad=$ binary value of 1 if Sea Tollway vessel sails from port $-u$ to port $-p$, with requirement $\sum_{p \in P} \delta_{T L}^{p}=1 ; 0$ if it is otherwise, $\sum_{p \in P} \delta_{T L}^{p}=0$,

$\rho_{P L}^{u p} \quad=$ binary value of 1 if Pelni vessel sails from port $-u$ to port $-p$ ; 0 if it is otherwise,

$y_{P R}^{p r} \quad=$ binary value of 1 if Pioneer vessel sails from port $-p$ to port $-r$, with requirement $\sum_{Y \in R} \lambda_{P R}^{Y}=1 ; 0$ if it is otherwise, $\sum_{\mathrm{Y} \in R} \lambda_{P R}^{Y}=0$

$x_{T L}^{\prime u p}=$ binary value of 1 if Sea Tollway vessel sails from port $-u$ dan stop by in port $-p$; 0 if it is otherwise

$\rho_{P L}^{\prime u p}=$ binary value of 1 if Pelni vessel sails from port $-u$ and stop by in port $-p ; 0$ if it is otherwise

$y_{P R}^{\prime p r}=$ binary value of 1 if Pioneer vessel sails from port $-p$ and stop by in port $-r ; 0$ if it is otherwise

\section{II.3.2 Upper Level Model}

In deciding the number of vessel $(N)$, the variables used are demand prediction $(D)$, vessel capacity $(V C)$, load factor $(L f)$, and planned number of trip $\left(n_{t}\right) . n_{t}$ of Pelni vessel is two times the number because the route is back-and-forth, meanwhile Sea Tollway and Pioneer are only once with milk run route. The determination of number of vessel does not include fixed cost variable because it is assumed that the value is equal for every vessel. Meanwhile, cost variable has been included in lower level model. The formulation of upper level model is:

$\operatorname{Min} N=$

$$
\left(\sum_{u \in U} \sum_{p \in P} D_{T L}^{\prime p} \cdot\left(V C_{T L} \cdot L f \cdot n_{t}\right)^{-1} \cdot x_{T L}^{\prime u p}\right)+
$$

$$
\begin{aligned}
& \left(\sum_{u \in U} \sum_{p \in P} D_{P L}^{\prime p} \cdot\left(V C_{P L} \cdot L f \cdot 2 n_{t}\right)^{-1} \cdot \rho_{P L}^{\prime u p}\right)+ \\
& \left(\sum_{p \in P r \in R} \sum_{P R} D_{P R}^{\prime r} \cdot\left(V C_{P R} \cdot L f \cdot n_{t}\right)^{-1} \cdot y_{P R}^{\prime p r}\right)
\end{aligned}
$$

Subject to

$$
\begin{aligned}
& n_{T L}=\sum_{u \in U} \sum_{p \in P} D_{T L}^{\prime p} \cdot\left(V C_{T L} \cdot L f \cdot n_{t}\right)^{-1} \cdot x_{T L}^{\prime u p} \\
& n_{P L}=\sum_{u \in U} \sum_{p \in P} D_{P L}^{\prime p} \cdot\left(V C_{P L} \cdot L f \cdot 2 n_{t}\right)^{-1} \cdot \rho_{P L}^{u p} \\
& n_{P R}=\sum_{p \in P} \sum_{r \in R} D_{P R}^{\prime r} \cdot\left(V C_{P R} \cdot L f \cdot n_{t}\right)^{-1} \cdot y_{P R}^{\prime p r} \\
& \sum_{p \in P} x_{T L}^{u p} \geq 0, \quad \sum_{p \in P} \rho_{P L}^{u p} \geq 0, \sum_{p \in P} y_{P R}^{p r} \geq 0 \\
& 0 \leq \sum_{p \in P} D_{T L}^{\prime p} \leq V C_{T L} \quad \forall p \in P \\
& 0 \leq \sum_{p \in P} D_{P L}^{\prime p} \leq V C_{P L} \quad \forall p \in P \\
& 0 \leq \sum_{r \in R} D_{P R}^{\prime r} \leq V C_{P R} \quad \forall r \in R \\
& \text { Lf } \geq 50 \% \\
& x_{T L}^{u p}, \rho_{P L}^{u p}, y_{P R}^{p r}, \in\{0,1\} \quad \forall u, p, r
\end{aligned}
$$


The purpose of upper level model is to minimalize the number of vessel $(n)$ that will be used to distribute freight (equation 1). Constraint (2) to calculate the demand for Sea Tollway vessel, constraint (3) to calculate the demand for Pelni vessel, and constraint (4) to calculate the demand for Pioneer vessel. Constraint (5) guarantees that all demand should be transported by vessel. Constraint (6)-(8) ensures that there must be freight transported and the number cannot be bigger than the vessel capacity, if the demand is higher than vessel capacity then the number of vessels must be increased. Constraint (9) shows that the vessel load factor is minimum $50 \%$, while constraints (10) is a binary number related to the decision for immediate stop in destination port.

\section{II.3.3 Lower Level Model}

The variables that affect the model formation are cost, time, distance, and vessel characteristic as certainty variables, while freight and wave height as uncertainty variable. Total cost $(C)$ covered in this model are transportation cost $\left(C_{t}\right)$, load cost $\left(C P_{b m}\right)$, storage cost $\left(C P_{s t}\right)$, and inventory cost $\left(C P_{i}\right)$, as shown in equation 11.

$$
C=C_{t}+C P_{b m}+C P_{s t}+C P_{i}
$$

$C_{t}$ represents transportation cost on the sea which is a function of voyage distance in sea mile $(w)$ and fuel consumption cost per sea mile $\left(C_{f l}\right)$ (equation 12 ), while $C_{f l}$ for every sea mile is shown by total fuel consumption per sea mile $\left(\mathrm{Co}_{f l}\right)$ and standard fuel price $\left(P_{f l}\right)$ (equation 13).

$$
\begin{aligned}
& C_{t}=w \cdot C_{f l} \\
& C_{f l}=C o_{f l} \cdot P_{f l}
\end{aligned}
$$

$C P_{b m}$ represent the total load and unload cost on port which is the function of freight quality $(\alpha)$, load and unload duration $\left(T_{b m}\right)$ and load and unload cost $\left(C_{b m}\right)$ (equation 14$)$.

$$
C P_{b m}=\alpha \cdot T_{b m} \cdot C_{b m}
$$

$C P_{s t}$ represents storage cost on port which is a function of freight quantity $(\alpha)$, storage duration $\left(T_{s t}\right)$ and storage cost $\left(C_{s t}\right)$ (equation 15).

$$
C P_{s t}=\alpha \cdot T_{s t} \cdot C_{s t}
$$

$C P_{i}$ represents inventory cost, both on sea and port, before tax which is a function of freight quantity $(\alpha)$, vessel intermediate stop duration on port $(t)$, voyage distance $(w)$, vessel speed $(V)$, load and unload cost $\left(C_{b m}\right)$, and freight inventory cost per time unit $\left(C_{i}\right)$ (equation 16).

$$
C P_{i}=C_{i}\left[\alpha\left(t+\frac{w}{V}\right)\right]+C_{i}\left(\frac{\alpha}{C_{b m}}\right)
$$

The amount of profit (Z) can be known from revenue accumulation $(R v)$ deducted by total cost $(C)$ (equation 17), where $R v$ value is a function of voyage distance $(w)$, distance unit transport cost $(\Phi)$, and freight quantity $(\alpha)$ (equation 18).

$$
\begin{aligned}
& Z=R v-C \\
& R v=w . \Phi . \alpha
\end{aligned}
$$

By substituting equation (18) and (11) to equation (17) value of profit is obtained $(Z)$ as shown on equation (19).

$$
Z=(w . \Phi . \alpha)-\left(C_{t}+C P_{b m}+C P_{s t}+C P_{i}\right)
$$

Value of profit shown on equation 19 is essentialy value of gross profit because it has not accommodated several costs such as vessel depreciation, capital cost, ABK cost, insurance, docking cost, anchored and moored cost, overbrengen cost, weighing cost and container certification cost.

On lower level model, there are three sea transport modes that will be integrated, in which each type of vessel has different capacity. The capacity of Sea Tollway and Pelni vessels are measured by TEUs (20 foot equivalent units) while Pioneer vessel with Ton. The formed model is stochastic and real time on the cargo and wave height variables. The service of Pioneer vessel is limited by clustering area, where vessel cannot serve port that is not in its cluster. Inter-cluster service will be given by Sea Tollway and Pelni vessels. The freight that moves between cluster must be transited first on collecting port. To accommodate real condition related to wave problem, when there is indication of wave with $3 \mathrm{~m}$ height or more on Pioneer route, the voyage will be rerouted to the nearest port, which is still under the service area. The port at which the intermediate stop is cancelled will be served by Sea Tollway vessel, if the draft of Sea Tollway vessel is smaller than the depth of port pool. If there is a condition where several vessels want to dock in port at the same time, the priority order is Sea Tollway vessel, followed by Pelni vessel and ended with Pioneer vessel. The trip is back and forth because Pelni vessel does not only transport freight but also carries passengers. All freights unloaded in port will be saved first in container yard or warehouse before being transported. The vessel capacity is capacitated, depend on the size of vessel.

The stochastic model of milk run with time windows (MRTW) has objective function to maximize gross profit from all vessel voyages. Therefore, based on equation (10), objective function (equation (20)-(23)) and constraints (equation (24)-(49)) are formed:

$\operatorname{Max} \quad n_{T L} \sum_{u \in U} \sum_{p \in P} Z_{T L} \cdot x_{T L}^{u p}+n_{P L} \sum_{u \in U} \sum_{p \in P} Z_{P L} \cdot \rho_{P L}^{u p}+n_{P R} \sum_{p \in P} \sum_{r \in R} Z_{P R} \cdot y_{P R}^{p r}$

where:

$$
Z_{\pi L}=\sum_{u \in U} \sum_{p \in P} w^{u p} \cdot \Phi_{T L}\left(\sum_{p \in P} \alpha^{u p}\right)-\left(\begin{array}{l}
\left.\sum_{u \in U} \sum_{p \in P} w^{u p} \cdot C_{f l T L}+\sum_{u \in U} \sum_{p \in P} \alpha^{u p} \cdot T_{b m T L}^{p} \cdot C_{b m T L}^{p}+\sum_{u \in U} \sum_{p \in P} \alpha^{u p}\left\{T_{s t}^{p} \cdot C_{s t}^{p}\right\}\right) \\
+C_{i k} \sum_{u \in U} \sum_{p \in P} \alpha^{u p}\left\{t_{T L}^{p}+\frac{w^{u p}}{V_{T L}}\right\}+C_{i k} \sum_{u \in U} \sum_{p \in P} \frac{\alpha^{u p}}{C_{b m T L}^{p}}
\end{array}\right)
$$




$$
\begin{aligned}
& Z_{F L}=\sum_{u \in U} \sum_{p \in P} w^{u p} \cdot \varphi_{P L}\left(\sum_{p \in P} \beta^{u p}\right)-\left(\begin{array}{l}
\sum_{u \in U} \sum_{p \in P} w^{u p} \cdot C_{f l P L}+\sum_{u \in U} \sum_{p \in P} \beta^{u p} \cdot T_{b m P L}^{p} \cdot C_{b m P L}^{p}+\sum_{u \in U} \sum_{p \in P} \beta^{u p}\left\{T_{s t}^{p} \cdot C_{s t}^{p}\right\}+ \\
C_{i k} \sum_{u \in U} \sum_{p \in P} \beta^{u p}\left\{t_{P L}^{p}+\frac{w^{u p}}{V_{P L}}\right\}+C_{i k} \sum_{u \in U} \sum_{p \in P} \frac{\beta^{u p}}{C_{b m P L}^{p}}
\end{array}\right) \\
& Z_{P R}=\sum_{p \in P} \sum_{r \in R} z^{p r} \cdot \Psi_{P R}\left(\sum_{r \in R} \sigma^{p r}\right)-\left(\begin{array}{l}
\sum_{u \in P} \sum_{p \in R} z^{p r} \cdot C_{f l P R}+\sum_{p \in P} \sum_{r \in R} \sigma^{p r} \cdot T_{b m P R}^{r} \cdot C_{b m P R}^{r}+\sum_{p \in P} \sum_{r \in R} \sigma^{p r}\left\{T_{s t}^{r} \cdot C_{s t}^{r}\right\}+ \\
C_{i g} \sum_{p \in P} \sum_{r \in R} \sigma^{p r}\left\{t_{P R}^{r}+\frac{z^{p r}}{V_{P R}}\right\}+C_{i g} \sum_{p \in P} \sum_{r \in R} \frac{\sigma^{p r}}{C_{b m P R}^{r}}
\end{array}\right)
\end{aligned}
$$

Subject to the following constraints:

$\sum_{u \in U} \sum_{p \in P} x_{T L}^{u p}=1 \quad, \forall u \in U, \forall p \in P$

$\sum_{p \in P} \sum_{r \in R} y_{P R}^{p r}=1 \quad, \forall p \in P, \forall r \in R$

$\sum_{u \in U} \sum_{p \in P} \rho_{P L}^{u p}=2, \forall u \in U, \forall p \in P$

$\sum_{p \in P} D_{T L}^{p} \sum_{u \in U} \sum_{p \in P} x_{T L}^{u p} \leq V C_{T L}, \forall u \in U, \forall p \in P$

$\sum_{p \in P} D_{P L}^{p} \sum_{u \in U} \sum_{p \in P} \rho_{P L}^{u p} \leq V C_{P L}, \forall u \in U, \forall p \in P(28)$

$\sum_{r \in R} D_{P R}^{r} \sum_{p \in P} \sum_{r \in R} y_{P R}^{p r} \leq V C_{P R}, \forall p \in P, \forall r \in R$

$\sum_{p \in P} x_{T L}^{p}-\sum_{p \in P} x_{T L}^{p+1}=0 \quad, \forall p \in P$

$\sum_{p \in P} \rho_{P L}^{p}-\sum_{p \in P} \rho_{P L}^{p+1}=0 \quad, \forall p \in P$

$\sum_{r \in R} y_{P R}^{r}-\sum_{r \in R} y_{P R}^{r+1}=0 \quad, \forall r \in R$

$\sum_{u \in U} \sum_{p \in P} x_{T L}^{u 0}=1$ and $\sum_{u \in U} \sum_{p \in P} x_{T L}^{0 p}=1, \forall u \in U, \forall p \in P$

$\sum_{u \in U} \sum_{p \in P} \rho_{P L}^{u 0}=1$ and $\sum_{u \in U} \sum_{p \in P} \rho_{P L}^{0 p}=1, \forall u \in U, \forall p \in P$

$\sum_{p \in P} \sum_{r \in R} y_{P R}^{p 0}=1$ and $\sum_{p \in P} \sum_{r \in R} y_{P R}^{0 r}=1, \forall p \in P, \forall r \in R$

( 1 , full cargo vessel condition, and there is freight to be unloaded in port $-p$, therefore number of freight that can be loaded $=\alpha^{\Psi F}-D_{\mathrm{TI}}^{p}$

1 , non full cargo vessel condition, and there is freight to be unloaded in port

$\sum_{p \in P} \delta_{T L}^{p}=\left\{\begin{array}{l}-p, \text { therefore the number of freight } \\ \text { that can be loaded }=V C_{T L}-\left(\alpha^{W}-\right.\end{array}\right.$ $\left.D_{\mathrm{II}}^{\mathrm{p}}\right)$

1 , non full cargo vessel condition, and there is no freight to be unloaded in port $-p$, then the number of freight that can be loaded $=V C_{\pi}-\alpha^{4 F}$

0 , full cargo vessel condition, and there is no freight to be unloaded in port $-p$

1 , full cargo vessel condition, and there is freight unloaded in port $-r$, therefore number of freight that can be loaded= $\mathscr{O D F}^{D P}-D_{P R}^{Z}$

1 , non full cargo vessel condition, and there is freight unloaded in port $-r$, therefore the number of freight that can be loaded $=V C_{P R}-\left(\sigma^{p y}-D_{\pi}^{p}\right)$

1 , non full cargo vessel condition, and there is no freight unloaded in port $-p$, then the number of freight that can be loaded $=V C_{P R}-\sigma^{p y}$
1 , if Sea Tollway vessel sails to port $-r$, the requirement is $X^{r}>£_{T L}$

0 , if it otherwise

$$
\begin{aligned}
& \sum_{p \in P} \sum_{r \in R} x_{T L}^{p r} \cdot \sum_{r \in R} \lambda_{T L}^{r}=\left\{\begin{array}{l}
\sum_{p \in P} \sum_{r \in R} y_{T L}^{p r} \cdot \xi=\sum_{r \in R} y_{P R}^{r+1}, \forall p \in P, \forall r \in R \\
\sum_{u \in U} \sum_{p \in P}\left(t_{T L}^{p}+\frac{V_{T L}^{u p}}{w^{u p}}\right) \cdot x_{T L}^{u p} \leq T_{T L}, \forall u \in U, \forall p \in P \\
\sum_{u \in U} \sum_{p \in P}\left(t_{P L}^{p}+\frac{V_{P L}}{w^{u p}}\right) \cdot \rho_{P L}^{u p} \leq T_{P L}, \forall u \in U, \forall p \in P \\
\sum_{p \in P} \sum_{r \in R}\left(t_{P R}^{r}+\frac{V_{P R}}{z^{p r}}\right) \cdot y_{P R}^{p r} \leq T_{P R}, \forall p \in P, \forall r \in R \\
t_{T L}^{d e p}=t_{T L}^{a r r}+t_{T L}^{p} \\
t_{P L}^{d e p}=t_{P L}^{a r r}+t_{P L}^{p} \\
t_{P R}^{d e p}=t_{P R}^{a r r}+t_{P R}^{r} \\
t_{T L}^{p} \leq 12 \\
t_{P L}^{p} \leq 6 \\
t_{P R}^{r} \leq 12 \\
x_{T L}^{u p}, \rho_{P L}^{u p}, y_{P R}^{p r}, \delta_{T L}^{p}, \lambda_{P R}^{r}, \xi \in\{0,1\}, \forall u, p, r
\end{array}\right.
\end{aligned}
$$

The lower level model is intended to maximize the gross profit on every vessel route (Sea Tollway, Pelni, and Pioneer). Constraints (24) illustrates that every Sea Tollway vessel can only make intermediate stop at the destination port for one time in one round voyage. Constraints (25) illustrates that every Pioneer vessel can only stop by at the destination port for one time in one round voyage. Constraints (26) illustrates that every Pelni vessel can only stop by at the destination port maximum two times in one round voyage. Constraints $(27,28$ dan 29$)$ declares that the total of freight request in destination port cannot exceed the capacity of each vessel. Milk run constraints are shown by the equation (30)-(25), where Sea Tollway vessel 
(constraints 30), Pelni (constraints 31) and Pioneer (constraints 32) visit the destination port to load and unload, then leaving the port to continue the voyage to another port until returning to the port of origin. Every Sea Tollway (constraints 33), Pelni (constraints 34), and Pioneer (constraints 35) vessel starts and ends its voyage from the port of origin and only pass through the port of origin when departing and returning. Uncertainty constraints are shown by equation (36)-(39). Sea Tollway vessels must stop by at port $-\mathrm{p}$, if there is freight that needs to be loaded, according to the condition shown on constraints (37). Constraints (38) and (39) are constraints on uncertainty variable, which is wave height. Constraints (38) is when there is freight that will be unloaded and loaded in port $-r$, but the wave $(\geq 3$ meter) causes the Pioneer vessel to not being able to stop by, therefore Sea Tollway vessel can stop by at port $-r$ if the depth of port $-\mathrm{r}$ pool is larger than the draft of Sea Tollway vessel. Constraints (39) when there is wave problem $(\geq 3$ meter) in port $-r$, therefore Pioneer vessel is rerouted to the next port -r. Time Windows constraints is shown on equation (40)-(48). The total time allocated to layover in port and voyage time should not be lager or equal with the planning time of one round voyage, Sea Tollway vessel TTL $=15$ days (constraints 40), Pelni vessel TPL $=20$ days (constraints 41) and Pioneer vessel TPR $=10$ days (constraints 42). The departure time of each vessel from the port must be the same with vessel's time of arrival in port of destination, plus the layover time at the port (constraints 43 , 44 and 45). The duration of vessel intermediate stop in port of destination is maximum 12 hours for Sea Tollway vessel (constraints 46) and Pioneer vessel (constraints 48), while it is 6 hours for Pelni vessel. Constraints (49) is a binary number related to the decision to load or not load cargo in the port, if there is cargo in port, and the height of wave around the port of destination.

\section{II.3.4 Algorithms}

The algorithms of upper level model completion are following this procedure:

Step 0: Initialization, $\mathrm{D}^{\mathrm{P}}$ is transported by Sea Tollway and Pelni vessels, while $\mathrm{D}^{\mathrm{r}}$ is transported by Pioneer vessel. It is determined that the minimum value of Lf is $50 \%$.

Step 1: Set data, making sure that every port of destination has the cargo that will be transported, $\mathrm{D}^{\mathrm{P}}$ and $\mathrm{D}^{T}>$ 0 and making it possible to exceed vessel capacity.

Step 2: Calculation, input every data in upper level model to determine optimal $n_{T L}, n_{P L}, n_{P R}$ Calculate the optimal number for each vessel using the equation(2) (4)

Step 3: Output optimization, if the optimal number of vessels has been found, then it is stopped; if it has not been found back to step 3 .
Algorithm for lower level model uses stochastic programming approach with Genetic Algorithm (GA). Model solving with python 3.7 software and the following procedure:

Step 0: Initialization, decide the number of $Q$ population, number of generation $=100$, elitsize $=3$ dan popsize $=5)$

Step 1: Fitness Evaluation, evaluate every $Q$ by calculating the fitness value of every chromosome and evaluating it until the criteria are filled. Maximize function $Z$, (equation 20) with the following:

1.1 (TL, PL, PR) take freight from port $i$, and check $\delta_{\pi}^{p}, \lambda_{P R}^{F}$ at port $i+1$

- If there is freight, vessel sails to port $i+1$

- If there is no freight, check all cycles

1.2 (PR) when vessel sails to port $i+1$, check $\xi_{\text {r }}$

- if $\xi_{r} \geq 3 \mathrm{~m}$, then PR vessel is rerouted to port $i+1$, and TL vessel that serves with requirement $X^{r}>£_{T L}$

- if $\xi_{r}<3 \mathrm{~m}$, check all cycles

1.3 (TL, PL, PR) check every $D_{\pi^{*}}^{g} D_{P L}^{g}, D_{P R}^{y}$ if all freights have been delivered.

- If true, simulation continues to step 2

- If false, waiting for the simulation iteration to be complete to return to step 1.1

Step 2: Crossover. Produce $Q_{t}$ hereditary population based on the best generation of fitness value. Add the string diversity on new population (offspring)

Step 3: Mutation; change the value of one gen in a chromosome, replace the lost gen from the population during the selection process and provide the gen that is absent on initial population.

Step 4: Elite insertion and repetition,

- Insert elite, from Step 2 to new population.

- If the termination condition, which is the maximum number of generations, is fulfilled, determine the last fitness value and stop. If it is not fulfilled, back to step 1

\section{COMPUTATIONAL EXPERIMENTS}

In this section, validation and sensitivity analysis are carried out from bi-level model based on the built algorithm, to ensure that this model is suitable for the application on actual condition in real world. Validation is carried out with empirical test based on the data that is close to the actual condition, with case study in Maluku Province, Indonesia.

The experiment of bi-level mode is carried out in two steps. The first step is simulating the number of vessels for the most optimal operation. The second step is simulating the optimal vessel network by using various condition. Data of freight distribution from port of origin to port of destination and value of demand estimation is given on table 1 .

Table 1. The origin of distribution destination and demand estimation

\begin{tabular}{|c|c|c|}
\hline $\begin{array}{c}\text { Origin } \\
\text { port } \\
(\text { code })\end{array}$ & Destination port (code) and demand estimation & Total \\
demand \\
estimation
\end{tabular}


International Journal of Engineering Research and Technology. ISSN 0974-3154 Vol.13, No.5 (2020), pp. 831-841

(C) International Research Publication House. https://dx.doi.org/10.37624/IJERT/13.5.2020.831-841

\begin{tabular}{|c|l|c|}
\hline $\mathrm{A}$ & $\mathrm{B}(5), \mathrm{C}(10), \mathrm{D}(2), \mathrm{E}(2), \mathrm{F}(5), \mathrm{G}(3), \mathrm{H}(10)$ & 37 TEUs \\
\hline $\mathrm{B}$ & $\mathrm{C}(12), \mathrm{D}(15), \mathrm{E}(17), \mathrm{F}(8), \mathrm{H}(8), \mathrm{I}(6), \mathrm{J}(15), \mathrm{K}(9), \mathrm{L}(6)$ & $95 \mathrm{TEUs}$ \\
\hline $\mathrm{C}$ & $\mathrm{D}(19), \mathrm{E}(15), \mathrm{F}(10), \mathrm{H}(14), \mathrm{I}(8), \mathrm{J}(10), \mathrm{K}(10), \mathrm{L}(9)$ & $96 \mathrm{TEUs}$ \\
\hline $\mathrm{D}$ & $\begin{array}{l}\mathrm{I}(26), \mathrm{J}(40), \mathrm{M}(18), \mathrm{N}(37), \mathrm{O}(50), \mathrm{P}(30), \mathrm{Q}(23), \mathrm{R}(36), \mathrm{S}(48), \mathrm{T}(26), \mathrm{U}(39), \mathrm{V}(27), \mathrm{W} \\
(35), \mathrm{X}(15), \mathrm{Y}(20), \mathrm{Z}(12), \mathrm{AA}(15), \mathrm{AB}(5), \mathrm{AC}(16), \mathrm{AD}(47)\end{array}$ \\
\hline $\mathrm{E}$ & $\begin{array}{l}\mathrm{G}(25), \mathrm{H}(40), \mathrm{AE}(20), \mathrm{AF}(37), \mathrm{AG}(31), \mathrm{AH}(20), \mathrm{AI}(37), \mathrm{AJ}(32), \mathrm{AK}(35), \mathrm{AL}(22), \mathrm{AM} \\
(28), \mathrm{AN}(26), \mathrm{AO}(35), \mathrm{AP}(49), \mathrm{AQ}(30), \mathrm{AR}(22), \mathrm{AS}(21), \mathrm{AT}(30), \mathrm{AU}(27), \mathrm{AV}(35),\end{array}$ \\
\hline $\mathrm{AW}(37), \mathrm{AX}(15), \mathrm{AY}(20), \mathrm{AZ}(13), \mathrm{BA}(38), \mathrm{BB}(30)$,
\end{tabular}

\section{III.1 Upper Level Simulation}

The simulation of number of vessels that will be operated is based on the demand in port of destination, vessel capacity, load factor and the planned number of trips. The determination of number of vessels is tactical planning, because vessel mobilization cannot be performed quickly. Therefore, the demand estimation used is a weekly average demand. The demand estimation on port of destination showed on table 1 must be transported by Sea Tollway vessels with capacity of 115 TEUs, Pelni vessels with capacity of 50 TEUs and Pioneer vessels with capacity of 500 Ton. The assumption of vessel's load factor is minimum of $50 \%$. The number of vessel trip is only once of Sea Tollway and Perintis vessels because its network model is milk run while Pelni vessel is estimated to have two times trip with back and foth network model. The optimization of equation (1) results in the simulation of number of vessels based on demand estimation on port of destination, shown on Figure 5.

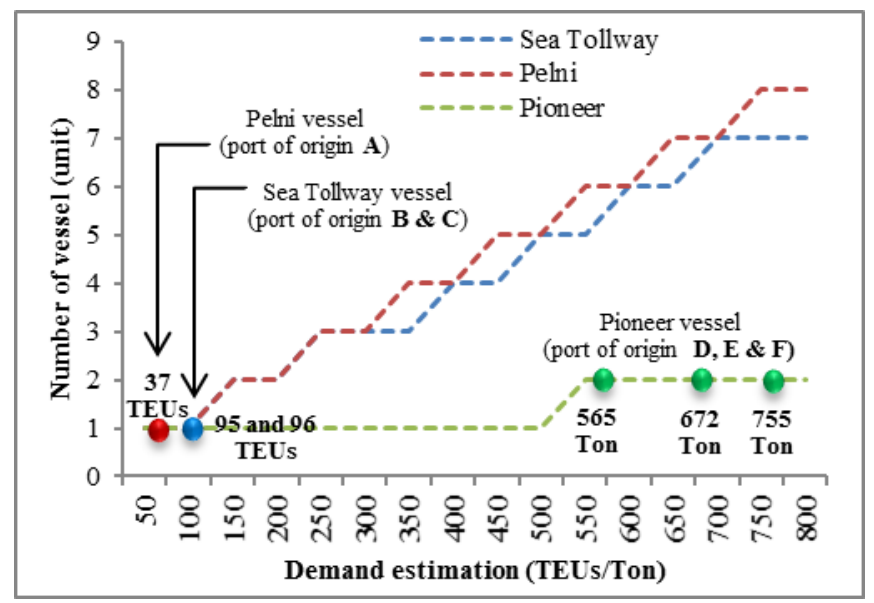

Fig. 5. Simulation of optimal number of vessels on demand estimation

Based on the simulation result of number of vessels (Figure 5 ), with estimation of number of demands of 37 TEUs in port of origin A, the number of Pelni vessels that are optimal to be operated is one vessel. For the demand estimation in port of origin B and C are 96 and 96 TEUs, it will need one Sea Tollway vessel. The demand estimation in port of origin $\mathrm{D}, \mathrm{E}$ and $\mathrm{F}$, are 565 Ton, 672 Ton and 755 Ton; each of them will need 2 Pioneer vessels.

With assumption that cargo is uncertainty variable with ever changing demand, the needed number of vessels must follow the real-time demand. This simulation is adjusted with the current vessel capacity. However, with the demand increase, increasing the vessel size might be needed to increase capacity. Upper level model implementation implicates on the optimal vessel allocation on every port of origin. The cost incurred for the non-operating vessel can be reduced by moving the vessel to other port of origin with higher demand.

In Indonesia, the number of vessels in every port of origin has been decided with assignment system without factoring the fluctuation in cargo. There is a condition where vessel that has received subsidy sails with very little cargo because the provision of subsidy-PSO from the government is based on the number of operating vessels per year, therefore the amount of subsidy is very high. By using this model, the subsidy on operating vessel that does not operate can be minimalized because there is no cargo. Next, the result of upper level model simulation is used as input on lower level model to optimize the vessel network with objective function of maximum profit.

\section{2 Lower Level Simulation}

This paper is validated based on freight distribution data on 83 ports, consists of 3 main port $(u), 9$ collecting port $(p)$ and 71 destination port $(r)$. The network of Sea Tollway and Pelni from port $-u$ to port $-p$ distributes 228 TEUs, the network of Perintis from port $-p$ to port $-r$ distributes 1.992 Ton. Simulation is carried out with genetic algorithm (GA) with 100 generation, using the number of vessels from the result of upper level model output. 
There are 3 compared scenarios; Scenario I: there is no clustering and there is no factoring on the effect of wave height uncertainty; Scenario II: there is clustering and there is no factoring on the effect of wave height uncertainty; Scenario III: there is clustering and the effect of wave height uncertainty is factored. In this case, clustering uses the result of previous research by Humang et al. [30].

The government currently implements the Scenario I, which is there is no clustering system implementation and Pioneer vessel serves destination port, which is far without the transit port. It causes the transport cost to be high. There is wave problem, but the route management is not implemented, which causes several ports to not be served. Scenario II assumes that the wave height is equal to (0), which means during the voyage round trip, there is no wave problem. In scenario II there is clustering. Scenario III assumes that there is clustering and there is also a wave problem that must be managed so that the distribution activity will keep running with the network reroute of Sea Tollway vessel.

The result of GA fitness value in Figure 6 shows that profit gained from the Scenario II is better when compared with Scenario I which is currently implemented by the government. This proves that clustering system application significantly increases profit. Meanwhile, when observing the wave variable in scenario III, profit will decrease because of vessel reroute, but it has an advantage, which is all demand still can be loaded. The comparison of profit from three scenarios can be seen on Figure 7.

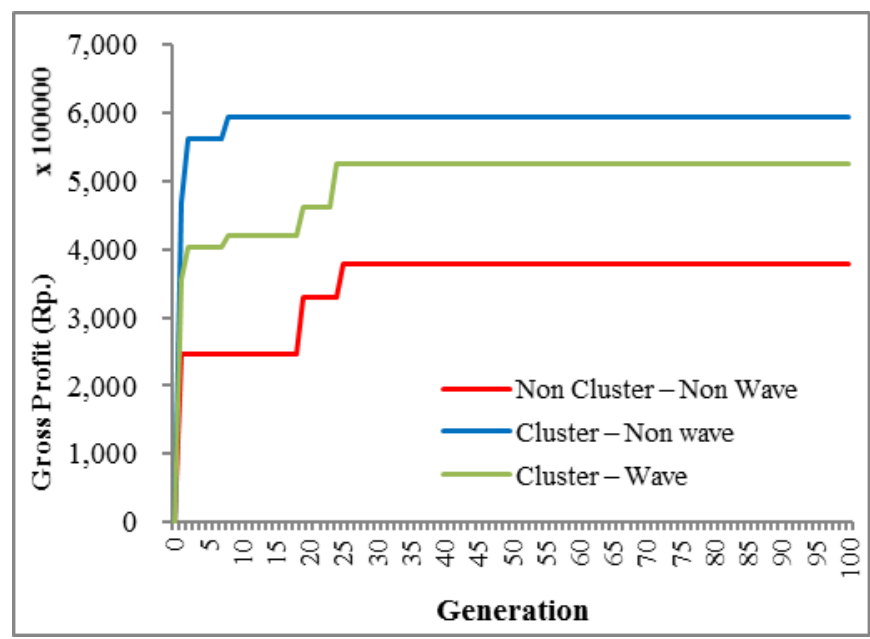

Fig. 6. The comparison of fitness value variation on clustering condition and wave uncertainty

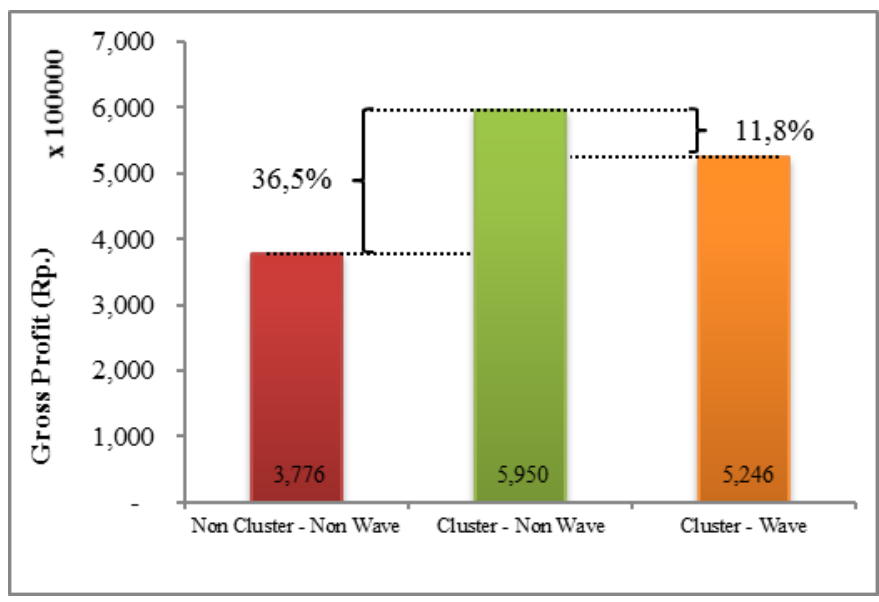

Fig. 7. The comparison of profit from lower level model

Figure 7 shows the profit comparison of three scenario. It can be seen that the implementation of cluster system (scenario II) will increase profit by $36,5 \%$ when compared to non-implementation of cluster (scenario I). In real condition where wave height always becomes the obstacle for Pioneer vessels in freight distribution, route management must be real time in a anticipating the obstacles of high wave (scenario III). In this case, port of destination that is affected by wave in scenario III is port $\mathrm{Q}, \mathrm{V}, \mathrm{X}, \mathrm{AC}, \mathrm{AE}$, AQ, AY, BA, BE, BN, BK, BH, and must be served by Sea Tollway vessels. The consequence is that the earned profit is decreasing by $1,8 \%$ when compared to condition without factoring the wave height (scenario II).

Based on the GA simulation on "cluster-non wave" "clusterwave" scenarios that are considered as the most optimal scenario, the route or network is received based on port of destination and type of vessel used, as stated in table 2 .

Table 2. The best route from the result of GA optimization based on port of origin

\begin{tabular}{|c|c|c|}
\hline $\begin{array}{l}\text { Port of origin } \\
\text { (Vessel) }\end{array}$ & $\begin{array}{l}\text { The optimal route for Scenario II "cluster-non } \\
\text { wave" }\end{array}$ & The optimal route for Scenario III "cluster-wave" \\
\hline $\begin{array}{l}\text { Tanjung Priok } \\
\text { (Pelni) }\end{array}$ & $\begin{array}{l}\mathrm{A} \rightarrow \mathrm{B} \rightarrow \mathrm{C} \rightarrow \mathrm{D} \rightarrow \mathrm{G} \rightarrow \mathrm{E} \rightarrow \mathrm{H} \rightarrow \mathrm{F} \rightarrow \mathrm{H} \rightarrow \mathrm{E} \rightarrow \mathrm{G} \rightarrow \mathrm{D} \rightarrow \mathrm{C} \rightarrow \mathrm{B} \\
\rightarrow \mathrm{A}\end{array}$ & $\mathrm{A} \rightarrow \mathrm{B} \rightarrow \mathrm{C}$ \\
\hline $\begin{array}{l}\text { Tanjung Perak } \\
\text { (Sea Tollway) }\end{array}$ & $\mathrm{B} \rightarrow \mathrm{C} \rightarrow \mathrm{L} \rightarrow \mathrm{K} \rightarrow \mathrm{F} \rightarrow \mathrm{D} \rightarrow \mathrm{J} \rightarrow \mathrm{I} \rightarrow \mathrm{E} \rightarrow \mathrm{H} \rightarrow \mathrm{B}$ & $\begin{array}{l}\mathrm{B} \rightarrow \mathrm{C} \rightarrow \mathrm{D} \rightarrow \mathrm{I} \rightarrow \mathbf{V} \rightarrow \mathrm{X} \rightarrow \mathrm{F} \rightarrow \mathbf{B E} \rightarrow \mathbf{B H} \rightarrow \mathrm{K} \rightarrow \mathrm{J} \rightarrow \mathrm{E} \rightarrow \mathrm{AY} \rightarrow \mathbf{B} \\
\mathrm{A} \rightarrow \mathrm{H} \rightarrow \mathrm{L} \rightarrow \mathrm{B}\end{array}$ \\
\hline $\begin{array}{l}\text { Makassar } \\
\text { (Sea Tollway) }\end{array}$ & $\mathrm{C} \rightarrow \mathrm{K} \rightarrow \mathrm{L} \rightarrow \mathrm{F} \rightarrow \mathrm{H} \rightarrow \mathrm{E} \rightarrow \mathrm{I} \rightarrow \mathrm{J} \rightarrow \mathrm{D}-$ & $\begin{array}{l}\mathrm{C} \rightarrow \mathrm{E} \rightarrow \mathbf{A Q} \rightarrow \mathbf{A E} \rightarrow \mathrm{D} \rightarrow \mathbf{Q} \rightarrow \mathbf{A C} \rightarrow \mathrm{F} \rightarrow \mathbf{B N} \rightarrow \mathbf{B K} \rightarrow \mathrm{K} \rightarrow \mathrm{I} \rightarrow \mathrm{J} \\
\rightarrow \mathrm{H} \rightarrow \mathrm{L} \rightarrow \mathrm{C}\end{array}$ \\
\hline $\begin{array}{l}\text { Ambon } \\
\text { (Pioneer -1) }\end{array}$ & $\begin{array}{l}\mathrm{D} \rightarrow \mathrm{M} \rightarrow \mathrm{N} \rightarrow \mathrm{J} \rightarrow \mathrm{P} \rightarrow \mathrm{O} \rightarrow \mathrm{Q} \rightarrow \mathrm{R} \rightarrow \mathrm{I} \rightarrow \mathrm{S} \rightarrow \mathrm{T} \rightarrow \mathrm{U} \rightarrow \mathrm{V} \rightarrow \mathrm{W} \\
\rightarrow \mathrm{X} \rightarrow \mathrm{Y} \rightarrow \mathrm{Z} \rightarrow \mathrm{AA} \rightarrow \mathrm{AB} \rightarrow \mathrm{AC} \rightarrow \mathrm{AD} \rightarrow \mathrm{D}\end{array}$ & $\begin{array}{l}\mathrm{D} \rightarrow \mathrm{W} \rightarrow \mathrm{U} \rightarrow \mathrm{T} \rightarrow \mathrm{I} \rightarrow \mathrm{S} \rightarrow \mathrm{N} \rightarrow \mathrm{J} \rightarrow \mathrm{P} \rightarrow \mathrm{O} \rightarrow \mathrm{R} \rightarrow \mathrm{M} \rightarrow \mathrm{AA} \rightarrow \mathrm{Z} \rightarrow \mathrm{Y} \\
\rightarrow \mathrm{AB} \rightarrow \mathrm{AD} \rightarrow \mathrm{D}\end{array}$ \\
\hline $\begin{array}{l}\text { Ambon } \\
\text { (Pioneer -2) }\end{array}$ & $\begin{array}{l}\mathrm{D} \rightarrow \mathrm{I} \rightarrow \mathrm{S} \rightarrow \mathrm{T} \rightarrow \mathrm{U} \rightarrow \mathrm{V} \rightarrow \mathrm{W} \rightarrow \mathrm{X} \rightarrow \mathrm{Y} \rightarrow \mathrm{Z} \rightarrow \mathrm{AA} \rightarrow \mathrm{AB} \rightarrow \mathrm{A} \\
\mathrm{C} \rightarrow \mathrm{AD} \rightarrow \mathrm{M} \rightarrow \mathrm{N} \rightarrow \mathrm{J} \rightarrow \mathrm{P} \rightarrow \mathrm{Q} \rightarrow \mathrm{O} \rightarrow \mathrm{R} \rightarrow \mathrm{D}\end{array}$ & $\begin{array}{l}\mathrm{D} \rightarrow \mathrm{W} \rightarrow \mathrm{Y} \rightarrow \mathrm{Z} \rightarrow \mathrm{AA} \rightarrow \mathrm{M} \rightarrow \mathrm{N} \rightarrow \mathrm{J} \rightarrow \mathrm{P} \rightarrow \mathrm{O} \rightarrow \mathrm{R} \rightarrow \mathrm{I} \rightarrow \mathrm{U} \rightarrow \mathrm{T} \rightarrow \mathrm{S} \\
\rightarrow \mathrm{AD} \rightarrow \mathrm{AB} \rightarrow \mathrm{D}\end{array}$ \\
\hline Tual & $\mathrm{E} \rightarrow \mathrm{AU} \rightarrow \mathrm{AV} \rightarrow \mathrm{AT} \rightarrow \mathrm{AQ} \rightarrow \mathrm{AH} \rightarrow \mathrm{AG} \rightarrow \mathrm{AP} \rightarrow \mathrm{AF} \rightarrow \mathrm{AE}$ & $\mathrm{E} \rightarrow \mathrm{AJ} \rightarrow \mathrm{AI} \rightarrow \mathrm{AK} \rightarrow \mathrm{H} \rightarrow \mathrm{AW} \rightarrow \mathrm{AU} \rightarrow \mathrm{AR} \rightarrow \mathrm{AS} \rightarrow \mathrm{AP} \rightarrow \mathrm{AO} \rightarrow$ \\
\hline
\end{tabular}


International Journal of Engineering Research and Technology. ISSN 0974-3154 Vol.13, No.5 (2020), pp. 831-841

(C) International Research Publication House. https://dx.doi.org/10.37624/IJERT/13.5.2020.831-841

\begin{tabular}{|c|c|c|}
\hline $\begin{array}{l}\text { Port of origin } \\
\text { (Vessel) }\end{array}$ & $\begin{array}{c}\text { The optimal route for Scenario II "cluster-non } \\
\text { wave" }\end{array}$ & The optimal route for Scenario III "cluster-wave" \\
\hline (Pioneer -1) & $\begin{array}{l}\rightarrow \mathrm{AO} \rightarrow \mathrm{G} \rightarrow \mathrm{AS} \rightarrow \mathrm{AR} \rightarrow \mathrm{AW} \rightarrow \mathrm{AL} \rightarrow \mathrm{AM} \rightarrow \mathrm{AN} \rightarrow \mathrm{BB} \rightarrow \\
\mathrm{BA} \rightarrow \mathrm{H} \rightarrow \mathrm{AJ} \rightarrow \mathrm{AK} \rightarrow \mathrm{AI} \rightarrow \mathrm{AZ} \rightarrow \mathrm{AY} \rightarrow \mathrm{AX} \rightarrow \mathrm{E}\end{array}$ & $\begin{array}{l}\mathrm{G} \rightarrow \mathrm{AF} \rightarrow \mathrm{AG} \rightarrow \mathrm{AH} \rightarrow \mathrm{AT} \rightarrow \mathrm{AV} \rightarrow \mathrm{AX} \rightarrow \mathrm{AZ} \rightarrow \mathrm{AL} \rightarrow \mathrm{AM} \rightarrow \mathrm{A} \\
\mathrm{N} \rightarrow \mathrm{BB} \rightarrow \mathrm{E}\end{array}$ \\
\hline $\begin{array}{l}\text { Tual } \\
\text { (Pioneer -2) }\end{array}$ & $\begin{array}{l}\mathrm{E} \rightarrow \mathrm{AW} \rightarrow \mathrm{AU} \rightarrow \mathrm{AV} \rightarrow \mathrm{AR} \rightarrow \mathrm{AS} \rightarrow \mathrm{AT} \rightarrow \mathrm{AQ} \rightarrow \mathrm{G} \rightarrow \mathrm{AO} \\
\rightarrow \mathrm{AE} \rightarrow \mathrm{AF} \rightarrow \mathrm{AP} \rightarrow \mathrm{AG} \rightarrow \mathrm{AH} \rightarrow \mathrm{AX} \rightarrow \mathrm{AY} \rightarrow \mathrm{AZ} \rightarrow \mathrm{AI} \rightarrow \\
\mathrm{BA} \rightarrow \mathrm{BB} \rightarrow \mathrm{AN} \rightarrow \mathrm{AM} \rightarrow \mathrm{AL} \rightarrow \mathrm{AK} \rightarrow \mathrm{AJ} \rightarrow \mathrm{H} \rightarrow \mathrm{E}\end{array}$ & $\begin{array}{l}\mathrm{E} \rightarrow \mathrm{AM} \rightarrow \mathrm{AN} \rightarrow \mathrm{BB} \rightarrow \mathrm{AI} \rightarrow \mathrm{AZ} \rightarrow \mathrm{AH} \rightarrow \mathrm{AG} \rightarrow \mathrm{AP} \rightarrow \mathrm{AF} \rightarrow \mathrm{G} \rightarrow \\
\mathrm{AO} \rightarrow \mathrm{AT} \rightarrow \mathrm{AS} \rightarrow \mathrm{AR} \rightarrow \mathrm{AV} \rightarrow \mathrm{AU} \rightarrow \mathrm{AW} \rightarrow \mathrm{AL} \rightarrow \mathrm{AK} \rightarrow \mathrm{AJ} \rightarrow \mathrm{H} \\
\rightarrow \mathrm{AX} \rightarrow \mathrm{E}\end{array}$ \\
\hline $\begin{array}{l}\text { Saumlaki } \\
\text { (Pioneer -1) }\end{array}$ & $\begin{array}{l}\mathrm{F} \rightarrow \mathrm{BU} \rightarrow \mathrm{BV} \rightarrow \mathrm{BW} \rightarrow \mathrm{BN} \rightarrow \mathrm{K} \rightarrow \mathrm{CB} \rightarrow \mathrm{CE} \rightarrow \mathrm{L} \rightarrow \mathrm{BZ} \rightarrow \mathrm{C} \\
\mathrm{C} \rightarrow \mathrm{CA} \rightarrow \mathrm{CD} \rightarrow \mathrm{BK} \rightarrow \mathrm{BL} \rightarrow \mathrm{BM} \rightarrow \mathrm{BJ} \rightarrow \mathrm{BY} \rightarrow \mathrm{BI} \rightarrow \mathrm{BH} \rightarrow \\
\mathrm{BF} \rightarrow \mathrm{BX} \rightarrow \mathrm{BG} \rightarrow \mathrm{BS} \rightarrow \mathrm{BR} \rightarrow \mathrm{BP} \rightarrow \mathrm{BE} \rightarrow \mathrm{BT} \rightarrow \mathrm{BO} \rightarrow \mathrm{BC} \\
\rightarrow \mathrm{BQ} \rightarrow \mathrm{F}\end{array}$ & $\begin{array}{l}\mathrm{F} \rightarrow \mathrm{BR} \rightarrow \mathrm{BS} \rightarrow \mathrm{BJ} \rightarrow \mathrm{BY} \rightarrow \mathrm{BI} \rightarrow \mathrm{BG} \rightarrow \mathrm{BX} \rightarrow \mathrm{BF} \rightarrow \mathrm{BW} \rightarrow \mathrm{BM} \\
\rightarrow \mathrm{BL} \rightarrow \mathrm{CD} \rightarrow \mathrm{CA} \rightarrow \mathrm{BZ} \rightarrow \mathrm{CC} \rightarrow \mathrm{L} \rightarrow \mathrm{CE} \rightarrow \mathrm{CB} \rightarrow \mathrm{K} \rightarrow \mathrm{BV} \rightarrow \mathrm{BQ} \\
\rightarrow \mathrm{BC} \rightarrow \mathrm{BO} \rightarrow \mathrm{BP} \rightarrow \mathrm{BT} \rightarrow \mathrm{BU} \rightarrow \mathrm{F}\end{array}$ \\
\hline $\begin{array}{l}\text { Saumlaki } \\
\text { (Pioneer -2) }\end{array}$ & $\begin{array}{l}\mathrm{F} \rightarrow \mathrm{BT} \rightarrow \mathrm{BE} \rightarrow \mathrm{BP} \rightarrow \mathrm{BO} \rightarrow \mathrm{BC} \rightarrow \mathrm{BR} \rightarrow \mathrm{BS} \rightarrow \mathrm{BG} \rightarrow \mathrm{BH} \rightarrow \\
\mathrm{BX} \rightarrow \mathrm{BF} \rightarrow \mathrm{BI} \rightarrow \mathrm{BJ} \rightarrow \mathrm{BY} \rightarrow \mathrm{CD} \rightarrow \mathrm{CA} \rightarrow \mathrm{CC} \rightarrow \mathrm{BZ} \rightarrow \mathrm{L} \rightarrow \\
\mathrm{CE} \rightarrow \mathrm{CB} \rightarrow \mathrm{K} \rightarrow \mathrm{BK} \rightarrow \mathrm{BL} \rightarrow \mathrm{BM} \rightarrow \mathrm{BN} \rightarrow \mathrm{BW} \rightarrow \mathrm{BV} \rightarrow \mathrm{BQ} \\
\rightarrow \mathrm{BU} \rightarrow \mathrm{F}\end{array}$ & $\begin{array}{l}\mathrm{F} \rightarrow \mathrm{CD} \rightarrow \mathrm{CC} \rightarrow \mathrm{BG} \rightarrow \mathrm{BI} \rightarrow \mathrm{BY} \rightarrow \mathrm{BJ} \rightarrow \mathrm{L} \rightarrow \mathrm{BZ} \rightarrow \mathrm{CA} \rightarrow \mathrm{CE} \rightarrow \mathrm{C} \\
\mathrm{B} \rightarrow \mathrm{K} \rightarrow \mathrm{BL} \rightarrow \mathrm{BM} \rightarrow \mathrm{BV} \rightarrow \mathrm{BW} \rightarrow \mathrm{BF} \rightarrow \mathrm{BX} \rightarrow \mathrm{BU} \rightarrow \mathrm{BQ} \rightarrow \mathrm{BC} \\
\rightarrow \mathrm{BS} \rightarrow \mathrm{BR} \rightarrow \mathrm{BO} \rightarrow \mathrm{BP} \rightarrow \mathrm{BT} \rightarrow \mathrm{F}\end{array}$ \\
\hline
\end{tabular}

The vessel route in table 2 is a route comparison when the effect of wave is and is not considered. Routes in scenario II changes to become routes in scenario III. The consequence is the increase in Sea Tollway vessel service operation and decrease in Pioneer vessel service operation. The Sea Tollway route that comes from port B after the changes is increasing in the number of vessel visitors to port $\mathrm{V}, \mathrm{X}, \mathrm{AY}$, $\mathrm{BA}, \mathrm{BE}$, and BH. Meanwhile, Sea Tollway route that comes from port $\mathrm{C}$ is increasing in the number of vessel visitors to port $\mathrm{Q}, \mathrm{AC}, \mathrm{AE}, \mathrm{AQ}, \mathrm{BK}$, and $\mathrm{BN}$. The changes in those routes is the result from the network integration in freight distribution process. When a Pioneer vessel cannot serve the destination port, the Sea Tollway vessel will substitute. Furthermore, the integration of service time in the node becomes more effective because there is time limitation for vessel intermediate stop in considering the loading and unloading activity.

Because bi-level model is stochastic and real time on the cargo and wave height, weekly time frequency must be run to ensure the accuracy of wave uncertainty variable. Cargo data is received real time from each port, while wave height data is received from the result of prediction by Meteorology, Climatology, and Geophysical Agency. The explained scenario on bi-level model will be made as policy alternative in route management, therefore the obstacle in freight distribution, especially the ones that is caused by wave factor can be minimized.

\section{III.3 The Analysis of sensitivity on Upper Level and Lower Level Model}

The level of sensitivity of earned profit on bi-level model can bee seen on the happening scenario. Generally, when comparing the clustering and non-clustering scenario, the earned profit looks higher when there is clustering system. The implementation of clustering system can shorten the service distance, which means the frequency of vessel service on each port is higher, the voyage cost will be lower. Whereas when comparing the wave variable in voyage activities, the ports unserved by Pioneer vessel still can be maximally serviced with network reroute of Sea Tollway vessel.

The sensitivity of earned gross profit from the effect from wave height is highly variable, depends on the number of affected destination port. However, with this model, these ports still can be served maximally by rerouting the Sea
Tollway vessel to serve the ports that are affected by high wave. Lastly, optimizing profit should be supported by the accuracy in the operating the number of optimal vessels. Using not optimal vessel will increase cost, and leads to the size of subsidy-PSO that must be given by the government. The illustration of sensitivity of bi-level mode can be seen in Figure 8.

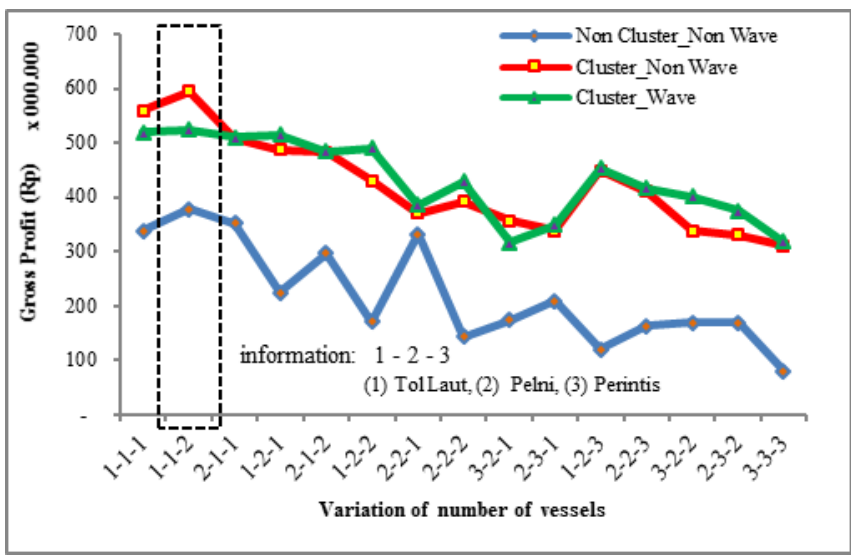

Fig. 8. The analysis of sensitivity from upper level and lower level model.

Based on the location of port of origin and demand estimation in Table 1, the analysis of sensitivity shows that to get highest gross profit, the number of optimal vessels that must be operated are: one Sea Tollway vessel, one Pelni vessel and two Pioneer vessels. The addition of vessels will significantly decrease the total gross profit. The result of analysis of sensitivity above can be used as decision making tool in choosing the number of vessels and which route that must be passed by every vessel. The decision can optimize the vessel profit which is expected to decrease the subsidyPSO given by the government in freight distribution on small, remote and cross-border islands in Indonesia.

\section{CONCLUSIONS}

Bi-level model in this paper can solve the network integration problem implemented on tactical planning and operational level. MRTW approach with real time data simulation is able to solve uncertain problems on cargo and wave height variables, and becomes the new contribution for the research on sea transport network integration. Uncertainty variables are used so that the constructed model 
can imitate real life condition. The model application should be managed in weekly basis because stochastic and dynamic situation can change at any moment. The operation of number of vessels are regulated based on freight demand on each port of origin.

The result of GA simulation shows that the cluster implementation can increase gross profit by $36,5 \%$ when compared to non-cluster system. If there is high wave, the government should manage the vessel network by integrating every vessel route so that the port of destination that is affected by wave can be served. However, the consequence is the gained gross profit is decreasing by $11,8 \%$ when compared to the condition where their wave height is not factored.

This bi-level model can be used as a decision-making system to optimize the number of vessels and for vessel network integration, therefore the allocation of subsidy-PSO by the government for freight distribution can be minimalized. The next research regarding the network optimization is preferably not only just port to port but should also be possible for port to door or even door to door and involves multi-mode.

\section{ACKNOWLEDGEMENTS}

The authors would like to express his special thanks and gratitude to Kementerian Riset, Teknologi dan Pendidikan Tinggi (Ristekdikti) and Indonesia Endowment Fund for Education (LPDP) for their funding used in completing the doctoral study in Universitas Indonesia

\section{REFERENCES}

[1] Jinca, M. Y. (2011). Transportasi Laut Indonesia (Analisis Sistem dan Studi Kasus). Surabaya: Brillian Internasional.

[2] Humang, W. P., Hadiwardoyo, S. P., \& Nahry. (2017). The Effectiveness of Pilot Marine Transport Services for Goods Distribution in Maluku Island Group, Indonesia. In 2017 6th IEEE International Conference on Advanced Logistics and Transport (ICALT) (pp. 165-169).

[3] SteadieSeifi, M., Dellaert, N. P., Nuijten, W., Van Woensel, T., \& Raoufi, R. (2014). Multimodal freight transportation planning: A literature review. European Journal of Operational Research, 233(1), 1-15.

[4] Sun, Y., Lang, M., \& Wang, D. (2015). Optimization models and solution algorithms for freight routing planning problem in the multi-modal transportation networks: A review of the state-of-the-art. The Open Civil Engineering Journal,9,714723.

[5] Bai, R., Wallace, S. W., Li, J., \& Chong, A. Y. L. (2014). Stochastic service network design with rerouting. Transportation Research Part B: Methodological, 60, 50-65.

[6] Meng, Q., Wang, T., \& Wang, S. (2012). Short-term liner ship fleet planning with container transshipment and uncertain container shipment demand. European Journal of Operational Research, 223(1), 96-105.

[7] Lium, A. G., Crainic, T. G., \& Wallace, S. W. (2009). A study of demand stochasticity in service network design. Transportation Science, 43(2), 144-157.

[8] Garrido, R.A., Mahmassani, H.S., 2000. Forecasting freight transportation demand with the space-time multinomial probit model. Transportation Research Part B 34 (5):403418.
[9] Sanchez-Rodrigues, V., Potter, A., Naim, M.M., 2010. The impact of logistics uncertainty on sustainable transport operations. International Journal of Physical Distribution \& Logistics Management 40, 61-83.

[10] Song, D. P., \& Dong, J. X. (2012). Cargo routing and empty container repositioning in multiple shipping service routes. Transportation Research Part B: Methodological, 46(10), 1556-1575.

[11] Olivo, A., Zuddas, P., Francesco, M.D., \& Manca, A., (2005). An operational model for empty container management. Maritime Economics and Logistics 7 (3), 199 222.Shen, W

[12] Demir, E., Burgholzer, W., Hrušovský, M., Arıkan, E., Jammernegg, W., \& Van Woensel, T. (2016). A green intermodal service network design problem with travel time uncertainty. Transportation Research Part B: Methodological, 93, 789-807.

[13] Chalumuri, R. S., \& Yasuo, A. (2014). Modelling travel time distribution under various uncertainties on Hanshin expressway of Japan. European Transport Research Review, 6(1), 85-92.

[14] Vettor, R., \& Soares, C. G. (2016). Development of a ship weather routing system. Ocean engineering, 123, 1-14.

[15] Walther, L., Rizvanolli, A., Wendebourg, M., \& Jahn, C. (2016). Modeling and optimization algorithms in ship weather routing. International Journal of e-Navigation and Maritime Economy, 4, 31-45.

[16] Zhang, M., Janic, M., \& Tavasszy, L. A. (2015). A freight transport optimization model for integrated network, service, and policy design. Transportation Research Part E: Logistics and Transportation Review, 77, 61-76.

[17] Halim, R. A., Kwakkel, J. H., \& Tavasszy, L. A. (2016). A strategic model of port-hinterland freight distribution networks. Transportation Research Part E: Logistics and Transportation Review, 95, 368-384.

[18] Ghane-Ezabadi, M., \& Vergara, H. A. (2016). Decomposition approach for integrated intermodal logistics network design. Transportation Research Part E: Logistics and Transportation Review, 89, 53-69.

[19] Fu, M. C., Hu, J. Q., Chen, C. H., \& Xiong, X. (2007). Simulation allocation for determining the best design in the presence of correlated sampling. INFORMS Journal on Computing, 19(1), 101-111.

[20] Oliveira, J. B., Lima, R. S., \& Montevechi, J. A. B. (2016). Perspectives and relationships in Supply Chain Simulation: A systematic literature review. Simulation Modelling Practice and Theory, 62, 166-191.

[21] Chica, M., Juan Pérez, A. A., Cordon, O., \& Kelton, D. (2017). Why Simheuristics? Benefits, Limitations, and Best Practices When Combining Metaheuristics with Simulation. Available at SSRN: https://ssrn.com/abstract=2919208.

[22] Layeb, S. B., Jaoua, A., Jbira, A., \& Makhlouf, Y. (2018). A simulation-optimization approach for scheduling in stochastic freight transportation. Computers \& Industrial Engineering, 126, 99-110.

[23] Güner, A. R., Murat, A., \& Chinnam, R. B. (2017). Dynamic routing for milk-run tours with time windows in stochastic time-dependent networks. Transportation Research Part E: Logistics and Transportation Review, 97, 251-267.

[24] Zhang, W., \& Xu, D. (2014). Integrating the logistics network design with order quantity determination under uncertain customer demands. Expert Systems with Applications, 41, 168-175.

[25] Saranwong, S., \& Likasiri, C. (2017). Bi-level programming model for solving distribution center problem: a case study in Northern Thailand's sugarcane management. Computers \& Industrial Engineering, 103, 26-39. 
International Journal of Engineering Research and Technology. ISSN 0974-3154 Vol.13, No.5 (2020), pp. 831-841

(C) International Research Publication House. https://dx.doi.org/10.37624/IJERT/13.5.2020.831-841

[26] Parvasi, S. P., Mahmoodjanloo, M., \& Setak, M. (2017). A bi-level school bus routing problem with bus stops selection and possibility of demand outsourcing. Applied Soft Computing, 61, 222-238.

[27] Bingfeng, S., Ming, Z., Xiaobao, Y., \& Ziyou, G. (2017). Bilevel programming model for exclusive bus lanes configuration in multimodal traffic network. Transportation research procedia, 25, 652-663.

[28] Liu, T., \& Ceder, A. A. (2017). Integrated public transport timetable synchronization and vehicle scheduling with demand assignment: A bi-objective bi-level model using deficit function approach. Transportation research procedia, 23, 341-361.

[29] Humang, W.P. Hadiwardoyo, S.P. \& Nahry, (2019a). Factors Influencing the Integration of Freight Distribution Networks in the Indonesian Archipelago: A Structural Equation Modeling Approach. Advances in Science, Technology and Engineering Systems Journal (ASTESJ). Volume 4, Issue 3, Page No 278-286

[30] Humang, W. P., Hadiwardoyo, S. P., \& Nahry (2019b). Clustering on freight distribution system in archipelagic region with deterministic allocation model. International Journal of Engineering Research and Technology, 12(12), 2997-3005. 